\title{
HLA-A*24:02 Positive Cells Present
}

National Cancer Institute

\section{Source}

National Cancer Institute. HLA-A*24:02 Positive Cells Present. NCI Thesaurus. Code

C142110.

A laboratory test result indicating the presence of HLA-A*24:02 positive cells in a tissue sample. 